\title{
TRADUÇÃO E LITERATURA: GREGO ANTIGO
}

\section{Mary M. de Camargo Neves Lafer*}

[...] não pode haver tradução total, nem sequer no interior de uma mesma língua (JAHANBEGLOO, 2000, p. 185).

Resumo: Este artigo pretende discutir algumas das principais dificuldades - gerais e específicas - que se apresentam ao tradutor do grego antigo para o português. Para exemplificar e apontar possivveis soluções, foi utilizada a tradução em versos de Os Trabalhos e os Dias, poema de Hesíodo, do século VIII a.C., feito pela autora.

Palavras-chave: Tradução. Tradução de poesia. Tradução do Grego antigo para o Português contemporâneo.

as sempre sábias palavras de Guimarães Rosa (apud RÓNAI, 2012, p. 7) 1 “Traduzir é conviver". É ter convivência com as duas línguas, saber metabolizar e mesmo ruminar o que se percebe na lingua original e, ao mesmo tempo, procurar a equivalência mais próxima possivel na língua-alvo, por meio de uma frequentação literalmente simpática.

Traduzir textos literários da língua grega antiga coloca, evidentemente, questões e problemas de natureza específica, devido à distância temporal entre as duas línguas e às características sintáticas e morfológicas distintas desses dois idiomas. Nosso depoimento comenta alguns aspectos da versão que fizemos de Os trabalhos e os dias de Hesíodo (2002), cuja primeira edição é de 1989. Tentaremos explicar, por meio de exemplificação, algumas questões peculiares à tradução deste poema do século VIII a. C.

Antes disso, entretanto, apresentaremos uma breve relação dos itens que devem ser observados pelo tradutor do grego antigo em sua trabalhosa tarefa. 
- Verificação do contexto histórico e literário da língua-fonte. Em nosso caso, levaremos em consideração elementos da tradição oral da literatura que encontramos enraizados em textos da época (epítetos, expressões formulares, aliterações, jogos de palavras e outros recursos mnemônicos).

- Transposição de elementos quantitativos - "breve-longa" - do idioma grego para as condições pautadas pelos elementos de tonicidade - "átono-tônico" - vigentes no português. Neste item, consideraremos ainda as dificuldades de se traduzir o hexâmetro grego e a possibilidade de traduzirmos verso por verso, respeitando o caráter linear do poema original (GRAMACHO, 2003).

- Manter certa eufonia na tradução, em consideração à forma original e ao público ouvinte desses poemas em recitações públicas, como era costume na Antiguidade em se tratando de uma sociedade majoritariamente sem competência para a leitura.

Os trabalhos e os dias se inicia com a palavra "Musa", como acontece com outros poemas desse período, como a Teogonia hesiódica, a Odisseia, e a Ilíada, em que ela é a terceira palavra. Esse posicionamento nesses textos poéticos pretende ter a força de uma convocação "física", pois, como se sabe, a presença da Musa traz consigo a eficácia da palavra poética. Quem fala pela boca do poeta é ela. O aedo incorpora a Musa; ele está a serviço de sua expressão.

Comecemos pelos dez versos iniciais, que constituem o "Proêmio" desse poema.

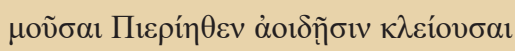

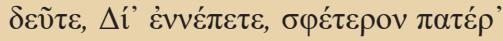
v $\mu v \varepsilon i_{0} \sigma \alpha \alpha$ :

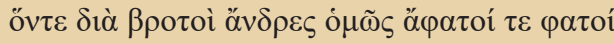
$\tau \varepsilon$,

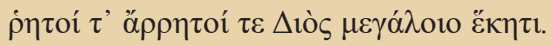

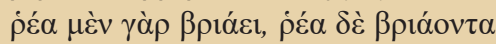
$\chi \alpha \lambda \varepsilon ́ \pi \tau \varepsilon 1$,

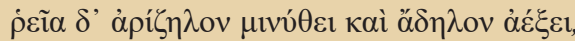


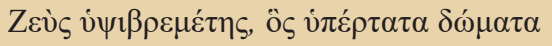
vaíct.

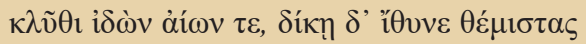

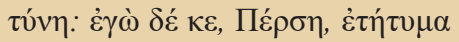
$\mu v \theta \eta \sigma \alpha i ́ \mu \eta v$.
Musas Piérias que gloriais com vossos cantos,

Vinde! Dizei Zeus vosso pai hineando.

Por ele mortais igualmente desafamados $e$ afamados,

Notos e ignotos são, por graça do grande Zeus.

Pois fácil torna forte e fácil o forte enfraquece,

Fácil o brilhante obscurece e o obscuro abrilhanta,

Fácil o oblíquo apruma e o arrogante verga Zeus altissonante que altíssimos palácios habita.

Ouve, vê, compreende e com justiça endireita sentenças

Tu! Eu a Perses verdades quero contar.

Logo no v. 3 temos um jogo de palavras que se opõem em sua significação, mas que partilham a mesma raiz.

"Por ele mortais igualmente desafamados e afamados" ("aphatói" / "phátoi”).

Da mesma forma, no v. 4, temos "notos e ignotos são, por graça do grande Zeus" ("rhetói" / "árrhetoi"). 
Essas equivalências em português não nos colocam problemas especiais, como fica evidente.

Os versos 5, 6 e 7 se iniciam pelo mesmo vocábulo "rhéia"/"rhéa", advérbio cuja tradução é "facilmente"/"fácil". Essa repetição é mantida em português. Aqui, o mesmo jogo de palavras dos versos 3 e 4 aparece, excetuando-se os versos 6 e 7, cujos pares de opostos não partilham a mesma raiz. Então, vejamos nossa versão:

\section{"fácil então torna o forte e fácil o forte enfraquece," ("briáei"/"briáonta") "fácil o brilhante obscurece e o obscuro abrilhanta," (arídzelon"/ "ádelon") "fácil o oblíquo apruma e o arrogante verga." ("skolión"/agénora").}

Quando não conseguimos manter os mesmos recursos da lingua grega em um único verso, tentamos colocá-lo no verso seguinte ou no anterior, mas é raríssimo isso acontecer.

Quanto aos epitetos, podemos observar alguns deles nessas linhas iniciais: "Musas Piérias" ("pieriethen"), nesse caso, optamos pelo uso de um helenismo visando à concisão do verso. "Pai" ("patér"), "Grande" ("megaloio") e "Altissonante" ("hypsibremétes") são epítetos de Zeus que ocorrem nesse trecho. Tentamos, sempre que possivel, manter as traduções dos epitetos em geral, conforme a escolha feita por J. A. A. Torrano em sua tradução da Teogonia de Hesíodo (1995), sendo nossa intenção uniformizar em português os epítetos que se repetem nos dois poemas. Entretanto, em alguns casos, quer pela economia do verso, quer por desejarmos enfatizar um determinado aspecto, optamos por outras traduções. Para exemplificarmos, vejamos o v. 48 no relato do mito de Prometeu e Pandora, onde preferimos a forma "de curvo-tramar" ("ankylométes") à "de curvo-pensar" por nos parecer mais adequado "tramar" para se transpor a ideia do modo de pensar e agir de Prometeu.

Algumas vezes é possivel, como nos versos do "Proêmio", verter de modo apropriado à nossa língua quase que palavra por palavra do texto original, na tentativa de resolver cada verso em uma única linha, respeitando, assim, a integridade do verso grego. Lembremos que o idioma helênico tem natureza mais sintética do que o nosso; basta observarmos que se trata de uma lingua com declinações e com tendência a formar palavras aglutinando à sua raiz partes de advérbios, verbos e outros substantivos. A característica da condensação - própria da poesia - é frequentemente perceptivel em grego, porém é bem mais custoso consegui-la em português. No v. 40, por exemplo, podemos ler

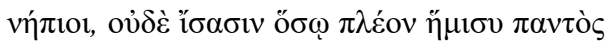

Néscios, não sabem quanto a metade vale mais que o todo

em que os sete vocábulos da língua-fonte foram traduzidos em onze da lingua-alvo, pois consideramos que a clareza da mensagem se sobrepõe à concisão do verso, por se tratar de uma máxima tradicional da cultura grega.

No relato do mito prometeico enfrentamos algumas dificuldades que talvez seja interessante apontar em um ensaio como este. 


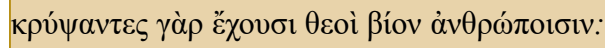

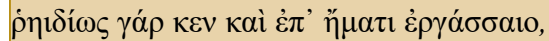


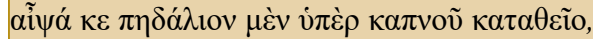

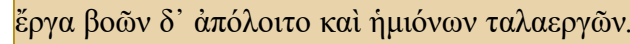

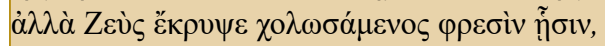

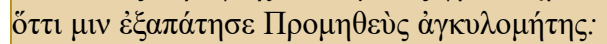

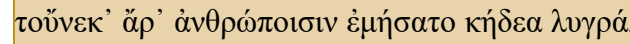

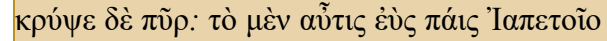

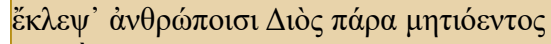

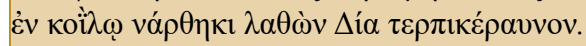

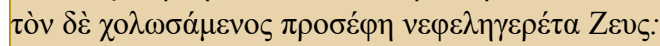

Oculto retêm os deuses o vital para os homens;

Senão comodamente em um só dia trabalharias

Para teres por um ano, podendo em ócio ficar;

Acima da fumaça logo o leme alojarias,

Trabalhos de bois e incansáveis mulas se perderiam.

Mas Zeus encolerizado em suas entranhas ocultou,

Pois foi logrado por Prometeu

de curvo-tramar;

Por isso para os homens tramou tristes pesares:

ocultou o fogo. E de novo o bravo filho de Jápeto

roubou-o do tramante Zeus para os homens mortais em oca férula, dissimulando-o de Zeus frui-raios.

Lemos no v. 45: "acima da fumaça logo o leme alojarias", em que temos a alusão a um processo de secagem do leme do navio desconhecido, ou esquecido, em nossos dias e que só se faz compreensivel por meio de uma nota-de-rodapé explicativa.

O v. 47 nos coloca diante de uma forma verbal "ocultou" ("ékrypse”), cujo objeto direto não aparece em sua posição usual, mas apenas no v. 50. Decidimos conservar essa mesma disposição para assinalar que o ocultamento do fogo se dá, de certa forma, também no nível sintático.
v. 47 "Mas Zeus encolerizado em suas entranhas ocultou"
v. 48 "pois foi logrado por Prometeu de curvo-tramar"
v. 49 "por isso aos homens tramou tristes pesares:"
v. 50 "ocultou o fogo. E de novo o bravo filho de Jápeto"
v. 51 "roubou-o do tramante Zeus para os homens mortais"
v. 52 "em oca férula, dissimulando-o de Zeus frui-raios."

Com o roubo do fogo divino, Prometeu oferece aos homens o fogo "técnico" e é justamente nesse trecho que se dá a passagem do fogo "natural" ao fogo "cultural”. O verso 52 também exige uma nota de rodapé para explicar esse modo de conservar e transportar o fogo aceso na parte oca da férula. Aqui observamos que, da mesma maneira que qualificamos o fogo de "cultural", podemos considerar Pandora também pertencente à esfera cultural e não à esfera da Natureza, pois, como o fogo, para ser feita, ela precisou de um engenho; ela foi "fabricada". Pandora, a primeira mulher, é quem - a partir da sua criação - traz a diferencia- 
ção entre homens ("ándres") e mulheres ("gynaikes”). Essa passagem acontece pela substituição da palavra "anthrópoi" (seres humanos) pelas outras duas mencionadas. Ainda no v. 52 observamos um epíteto não muito frequente para Zeus, "tramante" ("metióentos") que é da mesma raiz - "Métis" - que vimos no anteriormente citado epíteto de Prometeu, que, aliás a tem igualmente em seu nome. Curiosamente esse radical aparece no contexto de jogo e disputa entre Prometeu e Zeus, portanto, na qualificação desses dois personagens. Notemos que, se por um lado, Prometeu tem a astúcia no próprio nome, por outro, Zeus a tem dentro de si, pois sabemos que ele engoliu a deusa Métis, uma de suas esposas, ao saber que ela estava grávida de um filho seu. Temendo ser destronado por um futuro descendente, ele engoliu a deusa, que, assim, passou a fazer parte da sua constituição. Esse mesmo epiteto aparece no v. 104.

Outros epítetos mais habituais para qualificar Zeus ocorrem nesse trecho do poema e também na Teogonia e nos poemas homéricos: "frui-raios" ("terpikéraunon") o "agrega-nuvens" ("nephelegeréta"), "Cronida Rei" ("kroníuni ánakti"), "porta-égide" ("aigiókhou”), entre outros. Hefesto aí está com seus epítetos mais frequentes, "Coxo" ("amphigyéeis") e "inclito" ("klytós”).

Quanto ao hexâmetro, tipo de metro que dificilmente pode ser mantido em português com sucesso, foi usado por poucos tradutores no Brasil e em Portugal, sendo Carlos Alberto Nunes um deles em sua versão para a Odisseia. Sugerimos que o leitor leia a "Introdução" feita por Jair Gramacho à sua tradução dos Hinos Homéricos, em que ele faz um esclarecedor ensaio a respeito da dificuldade em se escolher um metro com equivalência adequada para traduzir o hexâmetro.

Em nossa experiência de tradução de poemas do período arcaico da literatura grega, consideramos que, para se respeitar o caráter linear do poema, o mais funcional e compatível com nossa língua é o verso livre, mas, claro está, sem abrir mão dos recursos sonoros que apontamos anteriormente, guardando, na medida do possivel, as características que vieram da tradição oral dessa literatura. Nossa opção por esse tipo de verso se deve ao fato de podermos com ele respeitar a linearidade dos versos e ao fato de não precisarmos retirar ou acrescentar um adjetivo sequer do original. Há também a questão dos neologismos e dos helenismos para se tentar obter concisão, foram evitados para que a tradução não ficasse "trôpega", entretanto gostaríamos de destacar o que ocorre no v. 64, "polidedáleo" ("polydáidalon”), helenismo escolhido por ser de fácil dedução: o prefixo "poli -", largamente empregado em nosso idioma, e o adjetivo "dedáleo", ligado ao nome de Dédalo, o mítico construtor do labirinto de Cnossos, significando, portanto, "complexo", "complicado", "intrincado".

Lembremos, por fim, a questão das etimologias, tão ricas e esclarecedoras nos textos gregos, porém dificeis de se transpor para nossa língua. Bom exemplo são os nomes próprios Pandora, Prometeu e Epimeteu. Em relação aos nomes dos dois irmãos, observamos que ambos têm "Métis" em sua composição, no primeiro vemos o prefixo "pro -" e no segundo, "epí -", respectivamente "antes" e "depois", ou seja, os nomes dos personagens já indicam as naturezas de ambos, um pode ter "a ciência dos fatos antecipadamente" e o outro tem "a ciência dos fatos, depois de terem acontecido". Pandora, cuja etimologia - "a que tem os dons de todos os deuses" - nos é dada pelo próprio poeta, igualmente aponta para a natureza dela, isto é, ela tem as caracteristicas divinas que lhe foram dadas pelos deuses convocados para confeccioná-la. 
Muito pode ser observado a respeito da tradução do grego antigo, aqui procuramos apontar apenas algumas questões enfrentadas na versão desta obra.

Parafraseando Umberto Eco (2003), diríamos que é preciso ter a noção de nossas limitações e aceitar que se pode chegar a "Dizer quase a mesma coisa", ou seja, nossa experiência de tradução vai chegar a dizer quase a mesma coisa que o original.

Para finalizar, estamos concordes com Paulo Rónai (2012, p. 182) quando afirma que "a tradução poética é muito mais trabalho de intuição do que de lógica e, sobretudo, que não existe tradução fácil”.

\section{Translation and literature: From ANCIENT Greek}

Abstract: This article aims to discuss some of the main difficulties, both of general and specific nature, confronted by the translator of ancient Greek into Portuguese. The article exemplifies and points out possible solutions based on the author's verse translation of Hesiod's poem Works and Days (VIII b.C.).

Keywords: Translation. Translation of poetry. From Ancient Greek to contemporary Portuguese.

\section{REFERÊNCIAS}

ECO, U. Dire quasi la stessa cosa. Milano: Studii Bompiani, 2003.

GRAMACHO, J. Introdução e tradução. In: Hinos homéricos. Brasília: Editora UnB, 2003.

HESÍODO. Teogonia - A origem dos deuses. Estudo e tradução de J. A. A. Torrano. 3. ed. São Paulo: Iluminuras, 1995.

HESÍODO. Os trabalhos e os dias. Tradução e comentários Mary M. de Camargo Neves Lafer. 4. ed. São Paulo: Iluminuras, 2002.

HOMERO. Odisseia. Tradução Carlos Alberto Nunes. 3. ed. Rio de Janeiro: Ediouro, 2001.

JAHANBEGLOO, R. Quatro entrevistas com George Steiner. Tradução Miguel Serras Pereira. Lisboa: Fenda Edições, 2000.

RÓNAI, P. Escola de tradutores. 7. ed. Rio de Janeiro: José Olympio, 2012.

Recebido em setembro de 2017.

Aprovado em setembro de 2017. 